\title{
El oriente de Chillida
}

\author{
Paloma Galante Rodero ${ }^{1}$ \\ (DEA UNED. DOCTORANDO DE LA UNED) \\ The east of Chillida
}

Dedico el artículo a mi directora del D.E.A Dra. Ma Teresa González Vicario (UNED) y al personal del Museo Chillida-Leku.

\begin{abstract}
RESUMEN
Todo el arte es influyente porque todo arte nace del hombre. Esta pequeña reflexión quiere resaltar cómo el arte y el pensamiento oriental han sido más influyentes, no sólo en el ámbito estético, sino en la concepción espacial y del propio hecho creador, en el arte occidental de lo que a primera vista podemos apreciar. En el caso de Chillida es una influencia no intencionada, muy sutil y analizada desde dos perspectivas, la primera, a partir de sus contactos directos con Japón como Homenaje a Hokusai, exposiciones realizadas y premios concedidos en el país nipón y por otro lado, los contactos indirectos con Oriente como su biblioteca personal, sus colaboraciones editoriales con Heidegger y Valente y su encuentro con Mark Tobey en la Bienal de Venecia de 1958.
\end{abstract}

PALABRAS CLAVE: Chillida, Oriente, MarK Tobey, Bienal de Venecia, Hokusai, Vacío, Heidegger, Jose Ángel Valente, Zen.

\begin{abstract}
All art is influential because all art is born of man. This short reflection wants to highlight how eastern art and Eastern thought have been most influential, not only in the aesthetic realm, in spatial conception and creative act, in Western art more than at first glance we can see. In the case of Chillida's unintentional influence, very subtle and analyzed from two perspectives, first from direct contacts with Japan as Tribute to Hokusai, exhibitions and prizes awarded in the japanese country, and on the other hand, indirect contacts with the East as his personal library, his collaborations with Heidegger and Valente and his encounter with Mark Tobey at the Venice Biennale of 1958.
\end{abstract}

KEY WORDS:

Chillida, East, Mark Tobey, Venice Biennale, Hokusai, Empty, Heidegger, Jose Ángel Valente, Zen.

1 Doctorado de la UNED. palomagalanterodero@yahoo.es 


\section{LA XXXIX BIENAL DE VENECIA, UNA ECLOSIÓN DE ORIENTALISMO}

Dentro de este ambiente efervescente de informalismo, una oleada de artistas conectados de una manera u otra con Japón van a eclosionar en uno de los acontecimientos artísticos más importantes del momento: la Bienal de Venecia.

Curiosamente la obra de dos de los artistas galardonados de esta XXIX edición de la Bienal de Venecia, Tobey en pintura y Chillida en escultura, estuvo influenciada por el arte y las sabidurías orientales, siendo de una manera más explicita en Tobey y más intuitiva en Chillida.

Ambos artistas son tratados de una manera conjunta por Kosme de Barañano en el Catálogo Chillida en San Sebastián y por José Ángel Valente en Elogio del Calígrafo. Así, Barañano establece un parangón entre Chillida-Tobey, considerando a Chillida el representante de la Escuela del Atlántico, mientras que la Escuela del Pacífico estaría ejemplificada por Mark Tobey².

"Sus dibujos son como olas suspendidas en el aire, escapadas del mar, mientras que en Tobey, la onda oriental se sumerge siempre en el continuo del agua: su costa es la del Pacífico, el camino de Oriente. La de Chillida es la del Atlántico, donde la escritura del mar es el romperse, fragmentarse en la roca».3.3

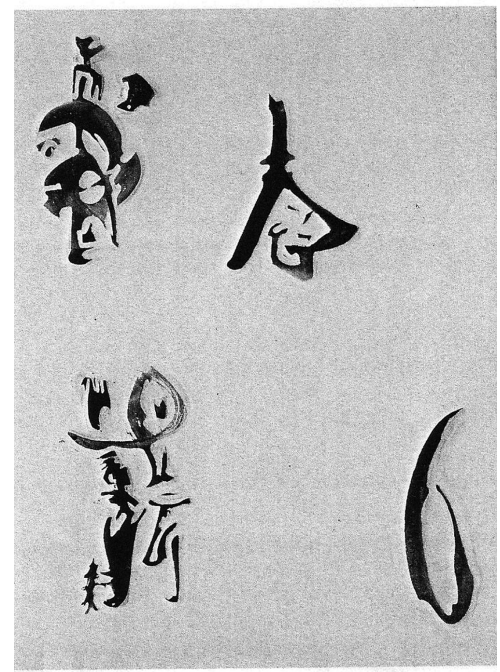

Fig. 1. Abstracts Figures, Mark Tobey, 1954, Acuarela y gouache sobre papel, $27 x 21 \mathrm{~cm}$, Colección particular. Fuente de procedencia: Catálogo de la exposición: Mark Tobey, MNCARS, 1997.

2 Hay que reconocer que el término de Escuela del Atlántico es novedoso, mientras que el de la Escuela del Pacífico (Mark Tobey, Sam Francis, Claire Falkenstein) fue dada por oposición a la Escuela de Nueva York.

${ }^{3}$ Catálogo de la Exposición Chillida en San Sebastián, Sociedad Guipuzcoana de Ediciones y Publicaciones, San Sebastián, 1992, pág. 28. 
Chillida en sus tintas y litocollages, entre 1948 y 1968, no siguió la teoría del color occidental, utilizó la simple mancha negra o tinta sepia sin más cromatismo. Por un lado se aleja del análisis del color impresionista y por otro, se aproxima a la tradición de la pintura china, tanto en los trazos caligráficos como en el uso del pincel, dejando que la tinta se exprese por si misma. Una de las características de la caligrafía y pintura oriental es expresar el movimiento y el reposo, el Ying y el Yang, para que puedan corresponderse lo interior con lo exterior. $Y$ así sucede en los dibujos y esculturas de Chillida, porque en ellos comulgan el espacio negativo y positivo, es decir, el espacio de la propia obra con el vacío interior del artista. El peldaño experimental que conformaron las tintas de Eduardo Chillida de entre 1948 y 1970 se pueden clasificar en tres momentos: hasta 1960 en las que las líneas son más rectas, a partir de esa fecha tienden a encorvarse y afinarse, $y$ a partir de 1970 se tornan más gruesas y lineales. Desafortunadamente, la mayoría de estas pequeñas tintas, tan inmediatas y sugerentes, no están fechadas, ni tituladas y pertenecen a colecciones particulares quedando, por lo tanto, sin configurar un catálogo razonado de las mismas.

"La caligrafía de Chillida, incluso en sus momentos orientalizantes, busca más la vibración de la línea o la dinamización del espacio que la concentración del trazo del expresionismo americano. Son si duda Tobey y Chillida quienes en el siglo $X X$ mejor han aunado las tradiciones plásticas orientales y occidentales». ${ }^{4}$

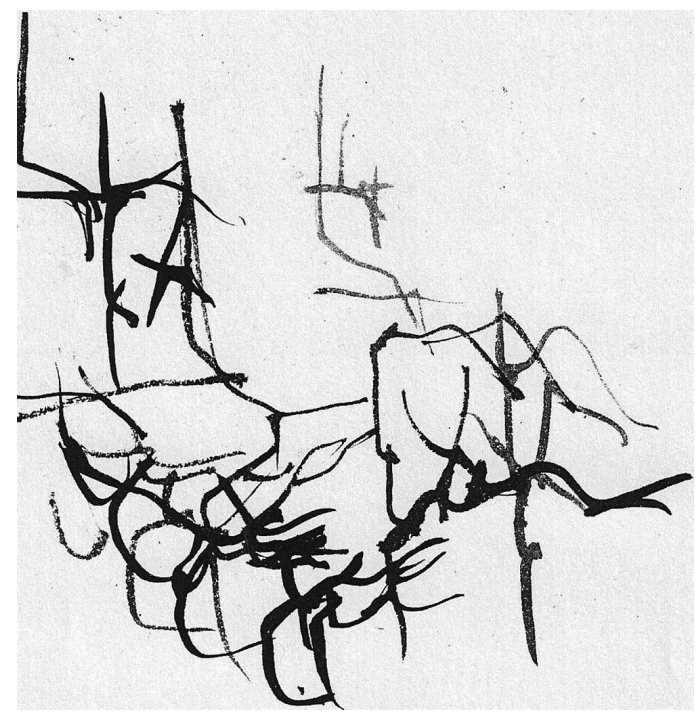

Fig. 2. Sin título, Chillida, 1957, Sepia, pincel sobre papel. S/L. Fuente de procedencia: Archivo gráfico del Museo Chillida-Leku.

${ }^{4}$ Catálogo de la exposición: Chillida, 1948-1998, Museo Nacional Centro de Arte Reina Sofía, Madrid, 15 de diciembre de 1998 al 15 de marzo de 1999. pág. 49. Cita que también se recoge en Elogio del calígrafo de José Ángel Valente. 
La diferencia entre ambos artistas reside en el aprendizaje y el acercamiento a la caligrafía oriental. En 1922, Tobey se traslada a Seatlle donde conoce al universitario chino Teng K' uei, quien le abre camino a la técnica caligráfica oriental. Doce años más tarde realiza un viaje a China y a Japón, donde pasará un mes en un monasterio zen a las afueras de Tokio. Esto va a ser el origen de sus majestuosos Sumi de 1957, tintas dónde desarrolla la técnica china del pincel de la Dinastía Tang y que fué implantada en la Dinastía Song. Ese mismo año lee a Suzuki y recibe en Seatlle las enseñanzas del maestro zen Takizaki. Tobey ${ }^{5}$, también recibió influencia del artista abstracto japonés Hasegawa, que en 1950 se traslada a California y contacta con Tobey, Kline y Kooning.

Tobey reconoció que ese gesto incondicional del acto creador era reflejo de su absoluta libertad interior y fruto de un estado de meditación. Chillida tampoco forzó las cosas, siempre dejaba que llegasen por sí mismas.

Sí, es verdad que la obra de Tobey estuvo marcada por unos contactos personales como con el mantenido con Teng K'uei al igual que la de Miró con Takiguchi, pero hay que decir que, a pesar de no tener un contacto directo de este tipo, el autodidactismo de Chillida desde sus comienzos, consiguió algo más difícil y complicado: que sus obras tuvieran eco oriental por la intuición del propio artista o, como el mismo Chillida lo denominaba, «aromas». Chillida, inconscientemente, se acercó a la caligrafía y sabiduría japonesa, no por apoyos o influencias foráneas, sino por su manera de pensar el arte.

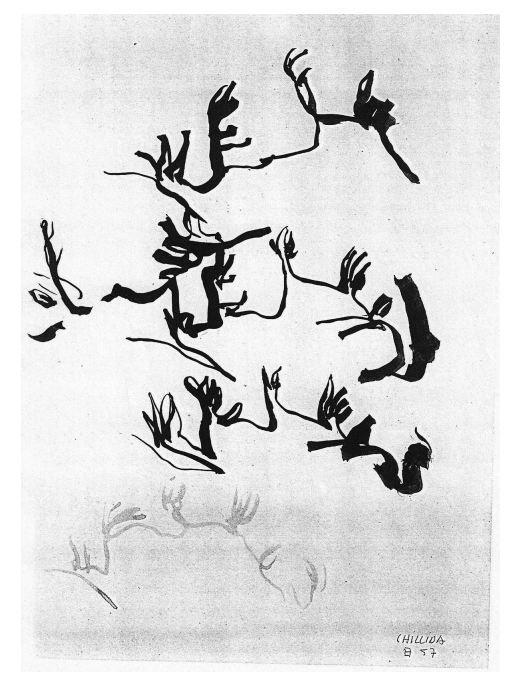

Fig. 3. Sin título, Chillida, 1957, Sepia, pincel sobre papel. S/L. Fuente de procedencia: Archivo gráfico del Museo Chillida-Leku.

5 Sobre Tobey y su relación con Oriente se han realizado dos exposiciones: En 2000, Zen und die westliche Kunst, Museum Bochum, Germany, y en 2006, La Tentation de l'Orient, Galerie Jeanne Bucher, Paris. 


\section{CHILLIDA: ENTRE LA TRADICIÓN MÍSTICA EUROPEA Y LA CORRIENTE ORIENTAL}

La historia de nuestro pensamiento occidental está marcada por la aversión al vacío, aversión que fue formulada mediante la famosa expresión horror vacui (horror al vacío), un vacío concebido como ausencia de lleno. Por el contrario, la concepción del vacío como seno potencial de formas se debe a Oriente y se remonta al siglo IV a. C. al tratado taoísta Tao Te Ching, donde se dice que lo que hace ser al recipiente es su vacío, su potencialidad para contener.

Pero hay una pequeña diferencia, muy difícil de apreciar entre el concepto del vacío místico y el proveniente de la tradición oriental. La nada mística se engloba dentro de la divinidad, mietras que el Tao oriental no se engloba dentro de ese concepto religioso, sino del Universo, lo que Shitao denominó «pincelada única».

"La nada budista no es el nihilismo sustancial de la tradición mística cristiana, no se trata de un anonadamiento pasivo, sino de una nada dinámica. (...) Igual que para Suzuki la mística cristiana no supera la dualidad entre el ser divino y el ser creado ${ }^{6}$.

En esta elocuente frase se encuentra la diferencia entre las dos concepciones del vacío que van a imperar en el arte de siglo XX, la de Rothko que está más cercana a la tradicción mística europea, como lo corrobora la teoría de Rosenblum, que se remonta al Romanticismo Nórdico de Friedrich fundamentada en las mística del Maestro Eckhart, y la que se acerca más a la concepción oriental, en la que se ubican artistas como Malevich y Tobey, mientras que en el limbo de ambas estaría Chillida.

"Chillida saw art as the expression of living energy and freedom existing in reality that can be found in both Nietzsche and Zen. This is the probably why we are so strongly drawn to his work»?.

Para el escultor vasco, el vacío además de ser un componente esencial de la obra es parte de la experiencia estética, de ahí que en una entrevista con Felix Maraña, ante la pregunta «¿Le preocupa más el lenguaje vacío o el espacio interior?», Chillida contestó:

«Todo va junto. El vacío también es una parte de nosotros, es un eco interior. Si embargo, el vacío interior no es tan desolador como la idea que tenemos del vacío. Personalmente creo que el vacío es necesario en todo-dentro y fuera-, porque sin vacío no hay nada; no hay diálogo y no hay arte»8.

6 VEGA, Amador: Zen y Mística y abstracción. Ensayos sobre el Nihilismo religioso. Editorial Trotta, Madrid, 2001, pág. 46.

7 Eduardo Chillida, febrero-abril 2006, Nagasaki Prefectural Art Museum; abril-mayo 2006, Mie Prefectural Art Museum; junio-julio 2006, Kamakura el Museo of Modern Art, Japón., pág. 168.

8 MARAÑA, Félix: «La mar ha sido mi amiga y maestra», Azul marino, no 6, mayo-agosto 1992, Madrid, págs.30-33. 
Chillida va a ser uno de los primeros artistas que rompa con la mirada artística occidental no entrenada a entender planamente el vacío, sobre todo en sus obras públicas como Homenaje a Hokusai, Peine de los Vientos, Gure Aiten Etxea, Elogio al Horizonte, etc. En ellas el espacio vacío, es un espacio relacional, cuya importancia reside en su vacuidad y en su relación con el entorno, cuestión de la que emana la importancia de la escala en sus obras. Esos espacios potencian el espíritu y la materia, que se complementan y se funden como el ying y el yang. También entra en juego lo que Chillida denomina el «espacio positivo», el volumen real de esa obra; en contraposición con lo que llamó «el espacio negativo» o el espacio que queda dentro de esa obra. Todas estas indagaciones del espacio por parte de Chillida han llevado a hablar del espacio heideggeriano en términos del espacio chillidico.

Su concepción plástica del vacío supuso un futuro en el destino del arte. El espacio de Chillida suma tanto el espacio místico de la tradición occidental como el espacio oriental de Lao Tse y, como bien intuyó Octavio Paz, refiriéndose al vacío de su obra, «Tiene todos los nombres y ninguno»?.

\section{CHILLIDA VERSUS HOKUSAI}

La montaña fue una obsesión en la vida y obra de Hokusai, «el viejo loco del pincel», y en la de Eduardo Chillida. Entre otros aspectos comunes que unen al pintor nipón y al escultor vasco, la montaña, un elemento aparente ingenuo en una pintura de paisaje, ha conseguido relacionar dos trayectorias artísticas diferentes en época, estilo y producción. Homenaje a Hokusailo fue el último homenaje que dedicó Chillida a su panteón de personajes. Pero el caso de Homenaje a Hokusai es muy especial por diferentes motivos. El primero es que junto a Tindaya, puede considerarse como una de sus obras más personales y ambiciosas artísticamente hablando. Además, ambas son las únicas dos obras inconclusas de Eduardo Chillida. A diferencia de Tindaya, cuyo proyecto está perfectamente detallado en el libro Montaña Tindaya: Eduardo Chillida ${ }^{11}$, el proyecto de Hokusai no está detallado en ninguna fuente escrita, a excepción del borrador del anexo de la Tesis Doctoral de Susana Chillida y su fruto, el documental. Tinda$y a^{12}$, no ha conseguido, por el momento, ver la luz, Homenaje a Hokusai, por el

9 PAZ, Octavio; MICHELIN, Guísele: Catálogo de la exposición Chillida, Galería Maeght, Maeght éditeur, París, 1979. pág. 9.

10 Homenaje a Hokusai, acero, 1992, Maeda Envioment Art.

11 BARAÑANO, Kosme de, y FERNÁNDEZ ORDÓÑEZ, Lorenzo: Montaña Tindaya: Eduardo Chillida, Las Palmas de Gran Canaria, Gobierno de Canarias, 1996.

12 De las últimas noticias que pude obtener de Tindaya en agosto de 2009 del personal de la biblioteca es la siguiente: «los estudios geológicos aprueban que el proyecto sería viable pero el tema está en manos de políticos, asunto que no interesa a la familia». 
contrario llegó a realizarse, pero sólo una parte, la pieza central. Curiosamente, son las dos únicas por las que Chillida se decanta a grabar la idea del proceso creador de una forma monográfica ${ }^{13}$.

Hokusai, fue considerado por Chillida como un pintor y dibujante «fantástico», un artista al que no le gustaron ni las cosas ni los caminos fáciles. Lo descubrió en la Biblioteca Nacional de París, cuando iba a conocer y a descubrir cosas nuevas. Le impactó por ser un personaje muy curioso, considerarndo que intuía antes que Kandisnky el arte de las no apariencias. Este descubrimiento de Chillida fue en 1941, momentos antes de que Braque le recomendara el libro del El Zen en el tiro con arco, y cuando se embarca en las tintas chinas y los litocolleges de los que se ha hablado en apartado anterior ${ }^{14}$.

En este sentido comentó en una entrevista a Felíx Maraña que en el año 1948, en París, pasaba horas en la Biblioteca Nacional donde descubrió la figura de Hokusai, "el viejo loco del dibujo», un dibujante nato que terminó diciendo: «si llego a los ciento uno o ciento diez, un punto o una raya roja que yo haga tendría vida». Esta frase que ha sido repetida en muchas entrevistas, es un claro síntoma de lo que llegó a sorprender a Chillida la frase tan visionaria de Hokusai, siempre remarcando que se había adelantado a Kandisnky. Desde entonces Chillida, como él mismo dijo: "Me enteré de quién era, y después iba a verle donde podía, en libros y en exposiciones; toda la vida (...) Entonces yo cogí bastante enchufe con estas cosas, y por eso le hice al cabo de los años un homenaje» ${ }^{15}$. Aunque no se cita en ninguna parte, posiblemente, y teniendo en cuenta la época, Chillida pudo ver en la Biblioteca Nacional de París el libro de Henry Focillon, Hokusai, publicado en 1914.

Antes de Homenaje a Hokusai, Chillida hace en 1974, a pequeña escala, un acero que con el tiempo le llamó La casa de Hokusai. La obra no se trató de un encargo, de hecho, el nombre le vino después. Llegó a la obra gracias a una pieza anterior que se titula La casa del poeta. Una vez que hizo la pieza, al ver las formas, éstas le recordaron a las olas de los cuadros de Hokusai, y como en ese momento se encontraba realizando sus conocidas "casas», decidió ponerle el título de La casa de Hokusai.

${ }^{13}$ CHILLIDA, Susana: De Chillida a Hokusai. Creación de una obra, producción Lorenzo Roca, La bahía audiovisual, Madrid, 1994.

SUÁREZ, Gonzalo (Dir.): Tindaya Chillida. Un proceso de creación. Zénit Producción, Gobierno de Canarias, 1997.

14 Muchas de estas tintas fueron expuestas en la exposición Eduardo Chillida, zeichnung als kulptur 1948-1989, celebrada en 1989 en de Städtisches KustMuseum Bonn, y Westfälisches Laudesmuseum Münster.

${ }_{15}$ El tono desenfadado de estas citas proviene del borrador de las trascripciones de la Tesis Doctoral: CHILLIDA, Susana.: Filming The Biography of an artist-father representation of self and other in ChiIlida art and dream, editada por Teachers college, Columbia University, Nueva York, 2000. 


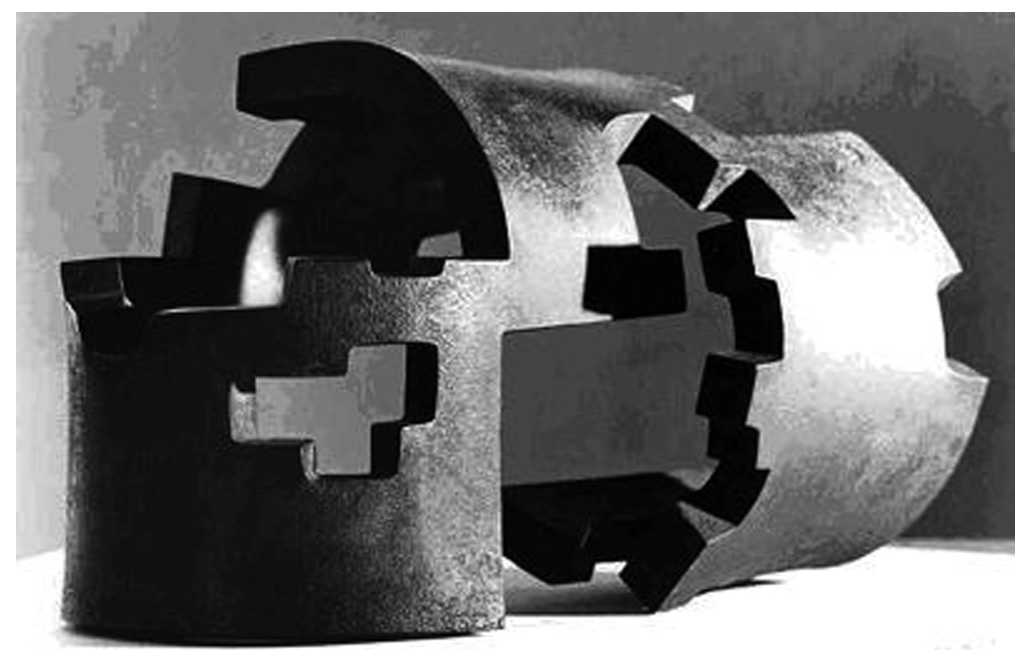

Fig. 4. La Casa de Hokusai, Chillida, 1981, acero cortén, 30 x 32 x 40cm., 26 kg, Colección Fundación Arte y Tecnología de Telefónica, Madrid. Fuente de procedencia: Archivo gráfico del Museo Chillida-Leku.

Años más tarde le llegaría el encargo desde Japón por parte de la familia Maeda de realizar la Casa de Hokusai a gran escala, a lo cual respondió Chillida que era imposible, ya que nunca se repetía. Aceptó el encargo con la condición de estudiar el emplazamiento por lo que se trasladó a Japón y allí encontró la perfecta ubicación.

Finalmente decidió que la obra se emplazaría en un valle a $40 \mathrm{~km}$ del monte Fuji, eligió ese enclave por su belleza natural, por la relación de Hokusai con el Monte que fue determinante en su obra y en su vida, recordemos las Treinta y Seis Vistas del Monte Fuji de Hokusai.

Homenaje a Hokusai goza de la originalidad de poseer, como Gure Aiten Et$x e a$, dos partes y un espacio deambulatorio. Una de las partes de hormigón y la otra de acero, aunque en Hokusai hay cinco partes de hormigón. Nunca un proyecto anterior entre sus obras públicas mostraba la novedosa estructura de $\mathrm{Ho}$ menaje a Hokusai.

La pieza central de acero mide $230 \times 230 \times 180 \mathrm{~cm}$, y pesa $18000 \mathrm{Kg}$. esta Pieza debía de estar rodeada por cinco elementos de hormigón de ocho metros de altura, para poder contemplar desde su orificio central al Fuji. Posiblemente tenga determinadas connotaciones, si en vida Hokusai miró a la montaña, ahora es la montaña la que mira a Hokusai. Al parecer, Chillida dijo en los Hornos de Reinosa que había que dejar que el material se expresara libremente, de acuerdo con sus propias leyes. Esta pieza de acero tardó en realizarse diez meses. Después vivió el 
proceso de oxidación que se produjo enfrente de Zabalaga, que hizo decir a Chillida que el acero conocería Euskalerría.

Chillida mencionó que la sección redonda central le recordaba a un abrazo dado a la tierra. Son formas que contrastan con las estructuras de hormigón vertical, en las que la obra mira hacia el centro de la tierra, intensificándose con ello la fuerza de la gravedad.

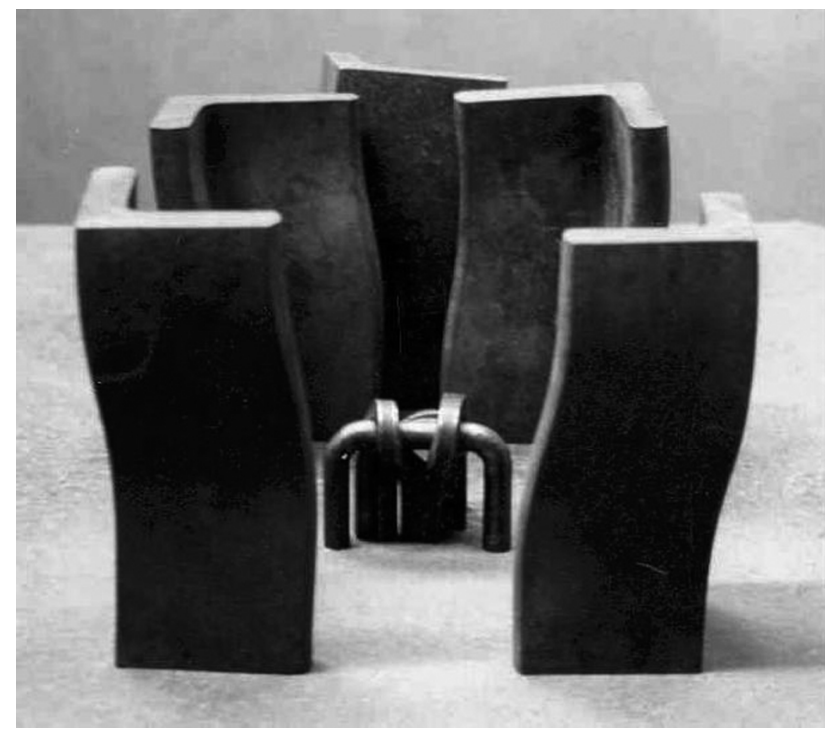

Fig. 5. Maqueta para Homenaje a Hokusai, Chillida $22 \times 43 \times 27 \mathrm{~cm}, 7,3 \times 9,2 \times 7 \mathrm{~cm}$ la parte central. Acero, 25 kg, Museo Chillida-Leku. Fuente de procedencia: Archivo gráfico del Museo ChillidaLeku.

Las piezas de hormigón no conocerían Hernani, por el problema del peso y del trasporte. Así, las cinco formas de hormigón son parecidas, como dice Chillida, pero no iguales, son como «los hombres» $y$ «las olas», parecidas pero diferentes. Estas cinco piezas, de $8 \mathrm{~m}$ de altura, recogen en su centro al acero. Algunos encofrados de poliespan se termiaron, pero las piezas de hormigón nunca llegaron a realizarse. Carlos Lizarriturry, miembro del equipo técnico de Chillida, estuvo más de un año en Japón pero nunca llegó a ver concluido el trabajo, muy lejos se quedaría del proyecto original. En un primer momento las obras se paralizaron por un terremoto que sacudió esa zona de Japón. La pieza central se instaló en un emplazamiento provisional en 1995. Para peor fortuna, la familia Maeda se arruinó y los bancos se debieron quedar con la obra. Homenaje a Hokusai nunca llego a instalarse en el emplazamiento pensado por Chillida. Una galería española viajó a Japón con intención de comprarla y recuperarla, pero fue infructuoso y en la actualidad se sigue sin conocer su paradero. 


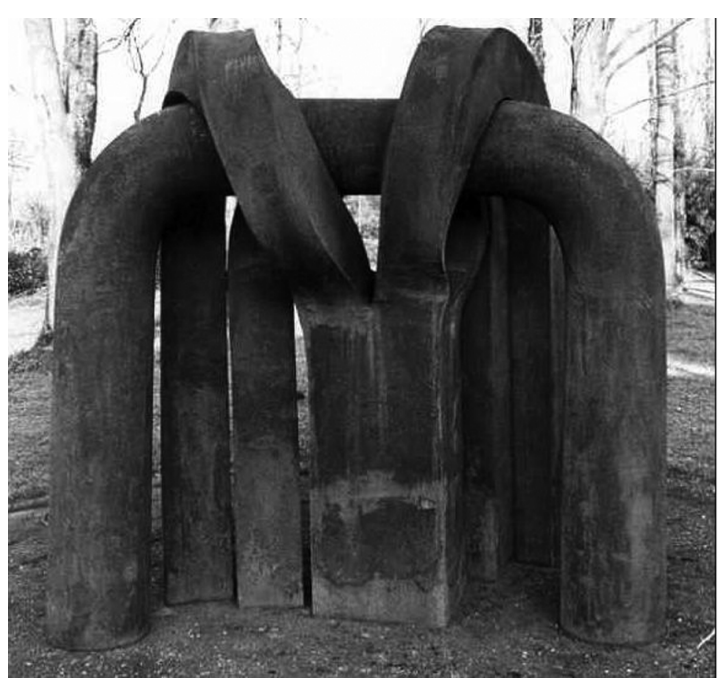

Fig. 6. Homenaje a Hokusai, Chillida, 1992, acero, 230 × 230 × $180 \mathrm{~cm}, 18.000 \mathrm{~kg}$, Maeda Enviromental Art Japon, Tokio. Fuente de procedencia: Archivo gráfico del Museo Chillida-Leku.

En esta obra se debaten las cuestiones decisivas de su trayectoria artística: la escala, el límite, el espacio y la montaña.

\section{OTROS CONTACTOS CON JAPÓN}

Chillida no sólo viajó a Japón para estudiar el emplazamiento de Homenaje a Hokusai, sino en otras ocasiones tan destacadas como fue recoger los galardones del Primer Premio del Ministerio de Asuntos Exteriores del Gobierno Japonés en la $\mathrm{X}$ Bienal de Grabado de Tokio, por el aguafuerte Euskadi IV y el Premio Imperial de Japón, la máxima distinción artística de este país, que le fue concedido en noviembre de 1991.

En junio de 2006 la exposición Eduardo Chillida viaja del 21 de febrero al 2 de abril, al Nagasaki Prefectural Art Museum, del 11 de abril al 21 de mayo al Mie Prefectural Art Museum y del 10 de junio al 30 de julio al Kamakura, el Museo of Modern Art. Los autores de los textos del catálogo de esa exposición itinerante fueron Toshio Yamanashi, Junji Ito y Kosme de Barañano.

El texto más destacable, por el tema en cuestión de la investigación, es el escrito por Junji Ito titulado The Key to the Universe: Thoughts on Eduardo Chillida. Curiosamente su autor inaugura el texto con estas palabras:

"Eduardo Chillida, a master of Spanish contemporary art, is relatively unknown in Japan compared to other Spanish masters such as Picasso, Miró Dalí and Tápies. I hope I am not the only one who finds this situation problematic because, in 
comparison with the other artists I have mentioned, Chillida has much in common with Japanese sensibility ${ }^{16}$.

\section{EL ARQUERO ZEN}

«(...) como un arquero zen» cita en su texto Clara Janes para referirse al escultor Vasco ${ }^{17}$. Aunque años antes era Octavio Paz quien decía "si Chillida fuese budista ${ }^{18}$, el primero en aventurarse y en percatarse de la resonancia oriental en la obra de Eduardo Chillida.

Uno de los libros fundamentales en su biblioteca, muy citado en entrevistas, obras y escritos sobre Chillida, es el Zen en el Arte del Tiro con Arco de Herrigel. Reconoció siempre y sin tapujos, sobre todo a partir de 1989, que la lectura de este libro le había dejado una profunda huella ${ }^{19}$. Llegó a sus manos gracias a que Jean Paulhan se lo entregase a Braque en la Galería de Maeght, poco después de que Chillida comprendiese la obra de Hokusai en la Biblioteca Nacional de París, ya que el libro de Herriguel fue traducido por primera vez del alemán al francés en 1955.

El libro Zen en el Arte del Tiro con Arco fue el fruto de la experiencia del autor con Japón. En 1924, Herrigel obtuvo una cátedra en la Universidad Imperial de Tohoku (Senday, Japón) para enseñar Historia de la Filosofía Occidental. Quiso aprovechar su estancia en Japón para profundizar sus conocimientos de budismo Zen. Ante esta iniciativa, el profesor Komachiya Sozo (1893-1979), le sugirió hacerlo a través de la práctica de algún arte marcial o expresión artística, decantándose así Herriger por la arquería.

Uno de los conceptos desarrollados en la obra de Herrigel es el «Satori»: «una especie de percepción interior: no la percepción de un objeto determinado, sino, por así decirlo, un estado perceptivo respecto a la verdadera realidad»20. En el prólogo de Zen en el arte del tiro con arco, Suzuki dice que «el hombre es un ser pensante, pero sus grandes obras las realiza cuando no calcula ni piensa» ${ }^{21}$, frase perfectamente aplicable cuando Chillida hablaba de los sueños que tuvo sobre

${ }^{16}$ Catálogo de la exposición de Eduardo Chillida; febrero-abril de 2006, Nagasaki Prefectural Art Museum; abril-mayo 2006, Mie Prefectural Art Museum; y junio-julio 2006, Kamakura el Museo of Modern Art, Japón, pág. 165. Traducción: Eduardo Chillida, un maestro del arte español contemporáneo, relativamente desconocido en Japón comparado con otros maestros españoles como Picasso, Miró, Dalí y Tàpies. Espero, y no soy el único, que encuentra esta situación anómala, porque en comparación con los otros artistas que he mencionado, Chillida tiene mucho en común con la sensibilidad japonesa.

17 JANÉS, Clara: La indetenible quietud: en torno a Eduardo Chillida, Siruela, Madrid 2008, pág. 105.

18 PAZ, Octavio; MICHELIN, Guísele: Catálogo de la exposición Chillida, Galería Maeght, Maeght éditeur, París, 1979, pág. 5.

${ }_{19}$ Catálogo de la exposición Chillida en San Sebastián, Sociedad Guipuzcoana de Ediciones y Publicaciones, San Sebastián, 1992, pág. 44.

20 HERRIGEL, Eugen: Zen en el arte del tiro con arco, Editorial Kier, Buenos Aires, 1999, pág. 32.

21 Ibidem, pág. 11. 
Tindaya y de los «aromas» previos a sus obras. Además de retomar el concepto del vacío como la característica fundamental de la pintura oriental, en la obra de Herrigel se habla de la «actitud no activa», es decir, del principio del wu wei, que consiste en dejar que las cosas fluyan libres de intención, «una vez sucedido esto el maestro ya no busca, encuentra» ${ }^{22}$, una frase con la que se puede identificar al escultor vasco, porque nunca buscó nada y siempre dejó que las cosas llegaran.

Otro de los libros de la biblioteca de Chillida fue el Tao Te Ching, que mediante la metáfora de la vasija nos explica a la perfección el concepto de la vacuidad oriental, tan presente en las afirmaciones que Chillida hizo sobre el espacio.

"La utilidad de una vasija reside en el vacío en el que se vierte el agua y no en la forma o en el material que está hecha, el espacio vacío es omnipotente puede contenerlo todo» (Tao Te Ching)»23.

¿Qué fuentes nos dan a conocer estos dos libros? Principalmente la obra y las declaraciones de Eduardo Chillida. Como fuente escrita podríamos destacar las trascripciones de la Tesis Doctoral de su hija Susana a las que puede acceder en la biblioteca del Museo Chillida-Leku. En esta sucesión de citas sin paginar puede apreciarse la importancia que el zen ha tenido en su vida y en su arte.

"Yo sentí, las primeras cosas que yo leí sobre Lao Tse y Confucio. Yo tuve...tuve una impresión, no diré de algo conocido pero algo que estaba más allá de lo que yo conocía, y que podía tener otra cara distinta. (...) Braque me habló a mi de un libro en el cual una persona, era alemán, un pintor alemán, iba a Japón a tratar de encontrar un maestro de pintura ZEN para poder entender, digamos, lo que supone lo del ZEN en la pintura (...). Es decir, nosotros los occidentales, creemos que para conseguir una cosa tenemos que desear conseguirla, y en cambio ellos, el ZEN, pretenden o incluso enseña que el deseo es lo que impide alcanzar lo que se desea. (...) y eso... a mi me sorprendió muchísimo. - Habla de Homenaje a Hokusai - (...) si se produce en muchas casos en mi trabajo (...) las cosas de ese libro son preciosas. VALENTE habla de eso también, que él sabía que yo había leído una cosa que yo había escrito de eso (...)».

Por otra parte, el libro de Herrigel va a ser citado por Valente en su poema XXXVI de su obra Treinta y siete fragmentos de 1971, y mientras que Kandisnky lo denominó «la visión interior», Chillida «aromas», Herrigel «Satori», Valente se referirá a la dimensión espiritual de la obra de arte como «estética de los vasos comunicantes» ${ }^{24}$. Esta dimensión espiritual de la obra de arte es lo que se denomina Chillida «aroma» y otros artistas lo han contemplado como la «dinámica interior».

22 Ibidem, pág. 70.

23 Cita de El libro del Té de Okakura Kakuzo, recogido en SAVIANI, C: Op. Cit., pág. 48.

24 VALENTE, José Ángel: Elogio del calígrafo: ensayos sobre arte, Valente, Galaxia de Gutemberg, Barcelona, 2002, pág. 37. 


\section{COLABORACIONES EDITORIALES}

Las colaboraciones editoriales que realizó Chillida a lo largo de toda su trayectoria artística desde 1956 hasta el año 2000 demuestran la relación que siempre tuvo con la tinta y el papel, los blancos y los negros, y la conexión entre la pintura y la poesía, que en cierta manera, puede compararse con las pinturas de paisajes chinos acompañadas de poemas. Porque mientras la poesía añade el vector tiempo, la pintura, o en este caso los litocollages de Chillida, añade el vector espacio. ¿Y qué mejor que el «arquitecto del vacío» para representarlo?

Analizando la colaboración conjunta con Martin Heidegger. Die Kunst und der Raum o El arte y el Espacio (Ed. St. Gallen, 1969), es donde se aprecia el víncuo teorético de la concepción espacial de Martin Heidegger, Eduardo Chillida y la filosofía oriental, en concreto con el taoísmo y el budismo zen, al partir de un espacio concebido no como carencia de lleno, sino como seno potencial de formas, un concepto que se aleja de la tradición espacial occidental fundamentada en el horror vacui. Esta concepción que quedó plasmada en su trabajo editorial Die Kunst und der Raum. Esta manera de meditar el espacio se acerca bastante a la idea del pensamiento taoísta, un espacio explicado con la metáfora del recipiente en el capítulo XI del Tao Te Ching de Lao Tse y con la vasija en el Libro del té de Kakuzo Okakura. Así mismo, Heidegger, en la conferencia «Das Ding» de 1950 («La cosa» traducida al castellano en 1994), añadió: «Esta nada en la jarra es propiamente lo que la jarra es». Curiosamente, Heidegger junto a Paul Shih-Yi Hsiao, miembro y pensador de la Escuela de Kioto, emprendió la traducción al alemán hasta el octavo capítulo del la obra de Lao-Tse, el Tao Te Ching ${ }^{25}$, la Biblia taoísta.

La Escuela de Kioto, contemporánea de Chillida y Heidegger, también estuvo marcada por la herencia del taoísmo y el budismo zen porque hicieron de la cuestión de la «Nada» el pilar básico de su pensamiento. Heidegger ya había tratado el espacio cuando abordó el tema del ser y del no-ser en su obra El Ser y el tiempo, Sein und Zeit (1927), donde plasmó que «la experiencia del ser nace de la experiencia del espacio». El espacio heideggeriano, como el chillídico, debe ser construido y vivido, no representado, porque para Heidegger las esculturas hacen el lugar, al igual que el no-ser no se concibe sin el ser.

A partir de 1920, Heidegger recibió como alumnos en la Universidad de Friburgo a los primeros pensadores de la Escuela de Kioto. Tras la traducción inconclusa del Tao te Ching al alemán (verano 1946), Hisao recuerda que el filosofo alemán conocía con anterioridad el texto por otras traducciones, afirmando que aquel trabajo ejerció una influencia significativa en Heidegger. También el filósofo Cheng-yuan Chang habló de la deuda de la filosofía heideggeriana con respecto al pensamiento taoísta, sobre todo por la cuestión del ser: el ser nace del no-ser, ya

${ }^{25}$ La obra de Lao Tse, puede aparecer como: Tao Te King, Dao de King o Tao Te Ching. En mi trabajo de investigación he optado por elegir Tao Te Ching. 
que en la filosofía occidental el no-ser ha sido considerado como «no es», una clara herencia de Parménides. Las enseñanzas orientales calaron más profundo de lo que se puede pensar en la filosofía heideggeriana, sin dudar de la madurez del pensamiento del filósofo alemán.

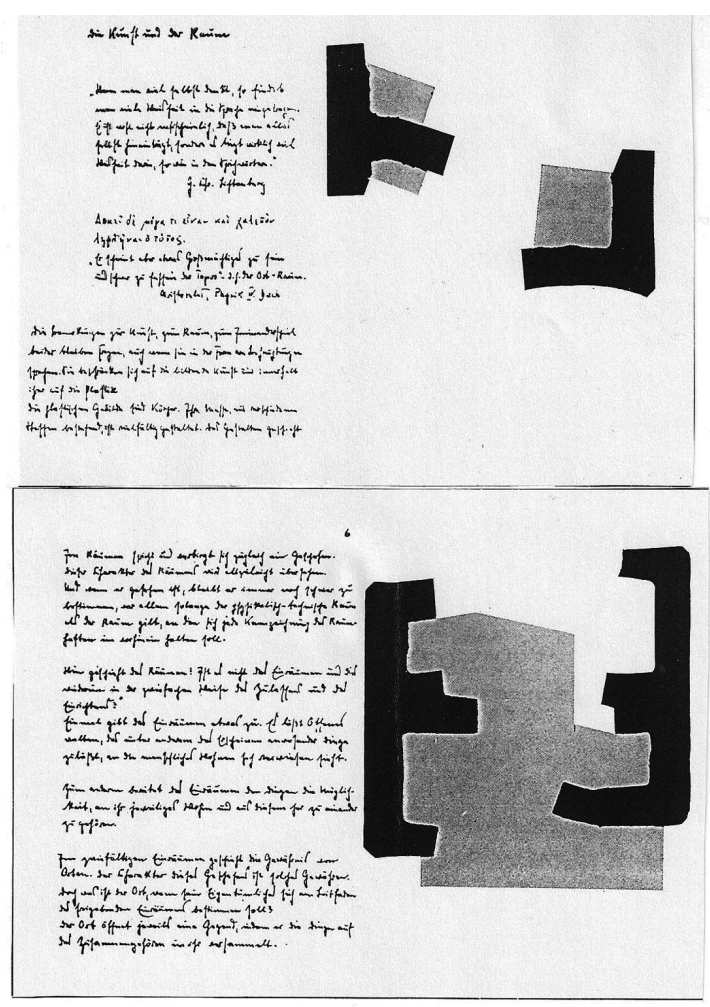

Fig. 7. Die Kunst und der Raum (El arte y el espacio), Martín Heidegger y Eduardo Chillida, 1969, Eker Presse de St. Gallen.

Chillida pensó su escultura igual que un filósofo piensa en el espacio y como un maestro budista medita acerca del arte, por otra parte, Heidegger conoció a ChiIlida en 1969, demasiado tarde para que el espacio heideggeriano influyese en la obra del escultor vasco, teniendo en cuenta que a finales de la década de los sesenta Eduardo Chillida ya contaba con una sólida trayectoria artística. Este filósofo vio en la obra del escultor vasco una evidencia práctica de sus teorías, una consideración que posiblemente a Chillida le motivase a consolidar más su camino.

Algunas de estas colaboraciones van a aportar a Chillida un contacto indirecto con Oriente, además de la estética japonesa de la que hacen gala algunos de los grabados que aparecen en las colaboraciones editoriales realizadas con Jorge Guillén, Clara Janés y José Ángel Valente, simpatizantes todos ellos, de una u otra forma, con la sabiduría oriental. 


\section{CONSIDERACIONES FINALES}

La obra de Eduardo Chillida ha sido admirada, galardonada y difundida por los cinco continentes. Y a pesar del enorme registro bibliográfico que acompaña a su ingente obra — síntoma claro de su potencialidad creadora - su obra sigue siendo estudiada, investigada y expuesta. Todo esto, unido a su personalidad arrolladora, son los motores por los cuales se puede seguir mirando su obra desde diferentes perspectivas, como su relación con oriente. Una resonancia ni forzada, ni aprendida, ni premeditada. Pero su eco oriental (Japón), no sólo se remite a lo puramente plástico (dibujos de tinta china sobre papel de los 50 a los 70), sino en el quehacer artístico, en la manera de pensar la obra de arte, en la forma de concebir el vacío como epicento de su obra, en su actitud ante la creación y en su posicionamiento con respecto a su obra, es ahí donde se encuentra su verdadera empatía con el arte y la sabiduría oriental.

La veta se abrió, y comenzaron a multiplicarse los comentarios al respecto, cuando el propio Chillida afirmaba y reconocía a finales de la década de los 80 , antes apenas lo había mencionado, las enseñanzas del libro de Herrigel, su admiración por Hokusai y el libro de Lao Tse.

La abstracción oriental no es tan personal como la occidental, los artistas remiten a un concepto puramente abstracto, en su proceso de despojamiento del yo. Se liberan del individualismo, tan potenciado en el mundo occidental y entran en comunión con el mundo. Eso es lo que le ocurre a la obra de Chillida, en todas sus manifestaciones artísticas, en sus lurras, en las gravitaciones, en sus tintas y en sus obras públicas.

La obra de Chillida seguirá dando mucho de que hablar no sólo porque su arte comulga con el misticismo y con el orientalismo, sino porque es una obra que ha sabido captar y aunar como pocas la tradición oriental y occidental, convirtiéndose en una de las grandes obras proféticas del siglo XX.

\section{BIBLIOGRAFÍA}

\subsection{El pensamiento y cultura oriental}

\section{Libros}

Cabañas, Pilar: La fuerza de Oriente en la obra de Joan Miró, Madrid, Electa, 2002.

CHENG, François: Vacío y plenitud, Siruela, Madrid, 1985. 
Herrigel, Eugen: El camino del zen, Paidos, Barcelona, 1999.

—: Zen en el arte del tiro con arco, editorial Kier, Buenos Aires, 1999.

HILLIER, Jack Ronald: Hokusai: paintings, drawings and woodcuts, Oxford: Phaidon Press Limited, 1978.

Kakuzo Okakura: El libro del té, Kairós, Barcelona, 1978.

LAO TSE: Libro del Tao (Tao Te King), Alfaguara, Madrid, 1978.

LaZAga, Noni: La Caligrafía Japonesa, Ediciones Hiperion, Madrid, 2007.

MAILlaRd, Chantal: La sabiduría como estética. China: Confucianismo, taoísmo y budismo, Ediciones Akal, Madrid, 2000.

Racionero, Luis:Textos de estética Taoísta, Alianza editorial, Madrid, 1983.

TÀPIES, Antoní y VALENTE, José Ángel: Comunicaciones sobre el muro, Ediciones de la Rosa Cúbica, Barcelona, 2004.

Tohru TAnABÉ: Hokusai, Anaya Editorial. Grandes Obras, Madrid, 1993.

VALENTE, José Ángel: Elogio del calígrafo: ensayos sobre arte, Valente, Galaxia de Gutemberg, Barcelona, 2002.

-: La experiencia abisal, Galaxia Gutemberg, Barcelona, 2004.

VEGA, Amador: Zen y Mística y abstracción. Ensayos sobre el Nihilismo religioso. Editorial Trotta, Madrid, 2001.

\section{Artículos}

Cabañas Moreno, Pilar: «Saura. París. Zen. Informalismo». Japón. Arte, Cultura y agua. Zaragoza, Asociación de Estudios Japoneses y Prensas Universitarias de Zaragoza. VII Congreso Internacional de la Asociación de Estudios Japoneses en España, 2004.

\section{Tesis doctorales}

VILLALBA, Javier: Budismo Zen: repercusiones estéticas en Oriente y Occidente, Dirigida por la Dra. Carmen García Ormaechea, Facultad de Historia del Arte, Universidad Complutense de Madrid, Madrid, 2003.

TSEng Huey-Chen, Reflexión sobre el espacio vacío. Un encuentro entre Occidente y Oriente en el ámbito del arte, Dirigida por el Dr. José Luis Molinuevo, Facultad de Filosofía, Universidad de Salamanca, Salamanca, 2003.

\section{Catálogos}

Barañano, Kosme M. de; Bärmann, Matthias; Schwarz, Dieter: Catálogo de la exposición Mark Tobey, Museo Nacional Centro de Arte Reina Sofía, Madrid, 1997. 


\subsection{Eduardo Chillida}

\section{Libros}

Amón, Santiago: Catálogo de la exposición Eduardo Chillida, Martin Heidegger, Jorge Guillén, Galería Turner, Madrid, 1974.

JANÉs, Clara: La indetenible quietud: en torno a Eduardo Chillida, Siruela, Madrid, 2008.

Bachelard, Gastón: La poética del espacio, Fondo de Cultura Económica, México, 1965.

Barañano, Kosme de, y Fernández Ordóñez, Lorenzo: Montaña Tindaya: Eduardo Chillida, Gobierno de Canarias, Las Palmas de Gran Canaria, 1996.

Barañano, Kosme de: Chillida, Heidegger y Husserl: el concepto del espacio en la filosofía y plástica del siglo XX, Universidad del País Vasco, San Sebastián, 1992.

-: Catálogo de la exposición Chillida en San Sebastián, Sociedad Guipuzcoana de Ediciones y Publicaciones, San Sebastián, 1992.

Barañano, Kosme Mํㅡㄹ de (coord.): I Symposium Chillida, IX Cursos de Verano, Universidad del País Vasco, San Sebastián, Julio-septiembre de 1990.

Barañano, Kosme Māa Álvarez Stelling, José y Savestrinı, Rita: Catálogo de la exposición Chillida. Escala Humana, Centro cultural Consolidado, Caracas, 1993.

Barañano, Kosme Mạa; Celaya, Gabriel y Meyer, Franz: Catálogo de la exposición Chillida. Escala Humana, Caja de ahorros de Gijón, Gijón, 1991.

Celaya, Gabriel: Los espacios de Chillida, Poligrafía, Barcelona, 1974.

CHILLIDA, Eduardo: Escritos de Eduardo Chillida, Editorial la Fábrica, Madrid, 2005.

-: Aromas, Museo Chillida-Leku, Hernani, 2004, (facsímile de Ediciones Edouard Weiss, París, 2000).

CHILLIDA, Susana (ed.): Elogio del horizonte. Conversaciones con Eduardo Chillida, Editorial Destino, Barcelona, 2003.

Chillida, Susana: Chillida, el arte y los sueños. Memoria de las filmaciones con mi padre, Universidad del País Vasco, Bilbao, 2003.

FullaOndo, Juan Daniel y MuÑoz, María Teresa: Laocoonte Crepuscular. Conversaciones en torno a Eduardo Chillida, Kain Editorial, Madrid, 1991.

Giovanni Caradete, Chillida, Poligrafía, Barcelona, 1999.

Martínez Aguinagalde, Florencio: Palabra de Chillida, Universidad del País Vasco, Bilbao, 1997.

Martínez Silvente, Ma José, (coord.): Chillida. Logos. Espacio de la palabra, Universidad de Málaga, Málaga, 2005

Paz, Octavio; Mıchelin, Guísele: Catálogo de la exposición Chillida, Galería Maeght, Maeght éditeur, París, 1979. 
UGALDE, Martín de: Hablando con Chillida escultor vasco, Editorial Txertoa, San Sebastián, 1975.

UGARTE, luxio: Chillida: Dudas y preguntas, Editorial Erein, San Sebastián, 1993.

\section{Tesis doctorales}

Barañano, Kosme de: La obra artística de Eduardo Chillida (Tesis Doctoral), publicada por la Universidad de Heidelberg, Alemania, 1984.

CHILLIDA, Susana: Filming The Biography of an artist-father representation of self and other in Chillida art and dream (Tesis Doctoral), editada por Teachers College, Columbia University, Nueva York, 2000.

\section{Catálogos}

- Chillida, 1948-1998, 15 de diciembre de 1998 al 15 de marzo de 1999, Museo Nacional Centro de Arte Reina Sofía, Madrid.

- De la mano al espacio, noviembre-diciembre 1998, Sala de Exposiciones Banco Zaragozano, Zaragoza.

- Chillida, del 20 de noviembre al 25 de enero del 2004, Fundación Joan Miró, Barcelona.

- Chillida obra gráfica completa, noviembre-diciembre 1977, Galería García Iolas-Velasco, Madrid.

- Reliefs Zeichnungen Collagen Druckgrafik, enero a febrero de 1970. Frankfurter KunstKabinett, Alemania.

- Eduardo Chillida, febrero-abril 2006, Nagasaki Prefectural Art Museum; abril-mayo 2006, Mie Prefectural Art Museum; junio-julio 2006, Kamakura el Museo of Modern Art, Japón.

- Los libros del artista Chillida: una constelación estética, del 6 de marzo de 20 de mayo de 2007, Biblioteca Nacional, Madrid.

- Texto inédito para el catálogo de la exposición en Tecla Sala de Hospitalet de Llobregat, prevista para septiembre de 2007.

\section{Publicaciones periódicas}

Amon, Santiago: «Número y pasión en la obra de Eduardo Chillida», Nueva Forma, no 26, marzo 1968, Madrid, págs. 37-44.

- «El arte y el espacio, un libro de Martin Heidegger y Eduardo Chillida», Nueva Forma, no 28, enero 1970, Madrid, págs.101-104 y 112-113.

- «Comentario a los comentarios de Eduardo Chillida», Nueva

Forma, no 84-85, enero-febrero 1973, Madrid, págs. 5-25 y 73-74. 
Fernández Ordóñez, Lorenzo: «Proyecto», Arquitectos, no 141, Colegio de Arquitectos de España, Vol. 96/3, abril de 1997, págs. 60-63.

FullaONDO, Juan Daniel: «El laberinto en la obra de Eduardo Chillida», Nueva Forma, no 22, noviembre 1967, págs. 45-62.

KORTADI Olano, Edorta: «El espacio en la escultura de Oteiza y Chillida «, en Mundaiz, no 58, Julio-Diciembre de 1999, Universidad de Deusto, San Sebastián, págs. 79-104.

MadriRejos, S. y SANCho, J. C: «Acerca de Tindaya», Arquitectos, № 141, Colegio de Arquitectos de España, Vol. 96/3, abril de 1997, págs. 58-60.

\section{Videograbaciones}

CHILLIDA, Susana: De Chillida a Hokusai. Creación de una obra, producción Lorenzo Roca, La bahía audiovisual, Madrid, 1994.

SuÁREZ, Gonzalo (Dir.): Tindaya Chillida. Un proceso de creación. Zénit Producción, Gobierno de Canarias, 1997. 
Cap15 14/11/2011 13:27 Página 374 